\title{
Genome-wide association study for cheese yield and curd nutrient recovery in dairy cows
}

\author{
C. Dadousis, ${ }^{*}$ S. Biffani,† C. Cipolat-Gotet, ${ }^{*}$ E. L. Nicolazzi,‡ G. J. M. Rosa,§ D. Gianola,§\# A. Rossoni,II \\ E. Santus,II G. Bittante, ${ }^{*}$ and A. Cecchinato*1 \\ *Department of Agronomy, Food, Natural Resources, Animals and Environment (DAFNAE), University of Padova, Viale dell'Università 16, \\ 35020 Legnaro, Italy \\ †Istituto di Biologia e Biotecnologia Agraria (IBBA), Consiglio Nazionale delle Ricerche (CNR), and \\ ‡Bioinformatics Core, Parco Tecnologico Padano, Via Einstein-Loc. Cascina Codazza, 26900 Lodi, Italy \\ $\S$ Department of Animal Sciences, and \\ \#Department of Biostatistics and Medical Informatics, University of Wisconsin, Madison 53706 \\ IIItalian Brown Breeders Association, Loc. Ferlina 204, Bussolengo 37012, Italy
}

\begin{abstract}
Cheese production and consumption are increasing in many countries worldwide. As a result, interest has increased in strategies for genetic selection of individuals for technological traits of milk related to cheese yield (CY) in dairy cattle breeding. However, little is known about the genetic background of a cow's ability to produce cheese. Recently, a relatively large panel $(1,264$ cows $)$ of different measures of individual cow CY and milk nutrient and energy recoveries in the cheese (REC) became available. Genetic analyses showed considerable variation for CY and for aptitude to retain high proportions of fat, protein, and water in the coagulum. For the dairy industry, these characteristics are of major economic importance. Nevertheless, use of this knowledge in dairy breeding is hampered by high costs, intense labor requirement, and lack of appropriate technology. However, in the era of genomics, new possibilities are available for animal breeding and genetic improvement. For example, identification of genomic regions involved in cow CY might provide potential for marker-assisted selection. The objective of this study was to perform genome-wide association studies on different CY and REC measures. Milk and DNA samples from 1,152 Italian Brown Swiss cows were used. Three CY traits expressing the weight (wt) of fresh curd (\%CY $\left.\mathrm{CY}_{\mathrm{CURD}}\right)$, curd solids (\% $\left.\mathrm{CY}_{\text {SOLIDS }}\right)$, and curd moisture $\left(\% \mathrm{CY}_{\mathrm{WATER}}\right)$ as a percentage of weight of milk processed, and 4 REC $\left(\mathrm{REC}_{\mathrm{FAT}}, \mathrm{REC}_{\mathrm{PROTEIN}}\right.$, $\mathrm{REC}_{\text {SOLIDS }}$, and $\mathrm{REC}_{\text {ENERGY }}$, calculated as the $\%$ ratio between the nutrient in curd and the corresponding nutrient in processed milk) were analyzed. Animals
\end{abstract}

\footnotetext{
Received June 10, 2016.

Accepted October 5, 2016.

${ }^{1}$ Corresponding author: alessio.cecchinato@unipd.it
}

were genotyped with the Illumina BovineSNP50 Bead Chip v.2. Single marker regressions were fitted using the GenABEL R package (genome-wide association using mixed model and regression-genomic control). In total, 103 significant associations (88 single nucleotide polymorphisms) were identified in 10 chromosomes $(2,6,9,11,12,14,18,19,27,28)$. For $\mathrm{REC}_{\mathrm{FAT}}$ and $\mathrm{REC}_{\text {PROTEIN }}$, high significance peaks were identified in Bos taurus autosome (BTA) 6 and BTA11, respectively. Marker ARS-BFGL-NGS-104610 ( 104.3 Mbp) was highly associated with REC PROTEIN $_{\text {and Hapmap52348- }}$ rs29024684 ( 87.4 Mbp), closely located to the casein genes on BTA6, with $\mathrm{REC}_{\mathrm{FAT}}$. Genomic regions identified may enhance marker-assisted selection in bovine cheese breeding beyond the use of protein (casein) and fat contents, whereas new knowledge will help to unravel the genomic background of a cow's ability for cheese production.

Key words: genome-wide association study, cheese yield, curd recovery, whey loss, dairy cattle

\section{INTRODUCTION}

Milk and dairy products are important components of the human diet and the proportion of milk used for manufactured products (e.g., cheese) is steadily increasing in many countries worldwide (Food and Agriculture Organization of the United Nations, 2015).

Milk characteristics (e.g., acidity and solid components, in particular casein and fat) are the cornerstone of cheese-making, and their role in this process has been previously investigated (Walstra et al., 2014). Moreover, milk coagulation properties (MCP) and curd firming modeling parameters $\left(\mathbf{C F}_{\mathrm{t}}\right)$, together with the phenomenon of syneresis, are considered crucial technological features for cheese production (Bittante et al., 2012). However, milk components and $\mathrm{MCP}-\mathrm{CF}_{\mathrm{t}}$ traits can 
only be used as indicators of the cheese-making process. On the other hand, traits such as the quantity of cheese obtained from a given amount of processed milk, or the recovery of milk components into the cheese, are direct measures of the cheese-making aptitude of milk and so are of great economic interest.

Although a considerable amount of literature on cheese-making is available, knowledge is mostly based on bulk milk. The importance of the percentage of cheese yield (\% $\mathbf{C Y})$ at the individual level (i.e., based on individual milk and not on bulk milk) has been pointed out by Othmane et al. (2002). Moreover, Banks (2007) discussed the significance of the recovery of milk constituents into the curd, as well as their loss in the whey for improved cheese quantity and quality. Previous studies have explored the potential of individual \% CY using bovine milk, albeit based on relative small numbers of individuals (Hurtaud et al., 1995; Wedholm et al., 2006). Recently, a large data set $(\mathrm{n}=1,264)$ of different measures of individual cow $\% \mathrm{CY}$ and milk nutrient and energy recovery in the cheese (REC) became available, using a cheese-making model approach assessed at the laboratory level (Cipolat-Gotet et al., 2013). Further analysis has shown important genetic variation in individual \% CY that does not solely depend on milk components but also relies heavily on the recovery of milk components in the curd (Bittante et al., 2013). Nevertheless, integration of the new knowledge into breeding programs is hampered by high costs, intensive labor requirements, and lack of appropriate technology.

At present, few potential alternatives have been suggested to overcome this problem (e.g., prediction of the aforementioned traits through infrared spectroscopy). Determination of milk components using spectral data is routinely used in the dairy industry (ICAR, 2012) and ongoing research is focused on the precision of the technology for predicting detailed milk components (Rutten et al., 2009), technological traits of milk such as milk coagulation (Cecchinato et al., 2009; Chessa et al., 2014), or different cheese measures (Ferragina et al., 2013; Bittante et al., 2014). On the other hand, genomic information offers a unique potential for a better understanding of the genetics underlying cheesemaking properties. A first step toward this direction is, for example, the application of genome-wide association studies (GWAS; McCarthy et al., 2008; Visscher et al., 2012) where thousands of DNA markers, in the form of SNP, are scanned throughout the entire genome (Bovine Genome Sequencing and Analysis Consortium et al., 2009) linking the phenotype of interest to specific regions on the genome (Goddard and Hayes, 2009). In addition, genomic information can be used in markerassisted or genomic selection breeding programs (God- dard and Hayes, 2009; de Los Campos et al., 2013; Van Eenennaam et al., 2014).

Genomic regions associated with bovine milk quality traits have already been identified in a variety of studies, either using a small number of preselected DNA markers or a whole genome scan, and candidate genes have been detected. In a GWAS study using HolsteinFriesian cattle, different protein variants (especially casein variants) showed high peaks on BTA6 and BTA11 (Schopen et al., 2011). Concerning MCP traits, milk coagulation has been associated with chromosomes 2 , 18, and 24 in Finnish Ayrshire cattle (Tyrisevä et al., 2008), whereas for rennet coagulation time, $\beta$-casein (CSN2), $\beta$-lactoglobulin $(L G B)$, and growth hormone 1 (GH1) have been identified as candidate genes (Bonfatti et al., 2010; Cecchinato et al., 2012, 2015). Moreover, $\mathrm{MCP}$ and some cheese characteristics have also been associated with $\kappa$-casein (CSN3), leptin ( $L E P)$, and leptin receptor (LEPR; Glantz et al., 2011). Recently, 2 GWAS studies identified other chromosomal regions associated with different $\mathrm{MCP}, \mathrm{CF}_{\mathrm{t}}$, and syneresis traits (Gregersen et al., 2015; Dadousis et al., 2016). Nevertheless, these studies have identified genomic regions associated with indicators and not with direct measures of the cheese-making aptitude of milk.

The objective of our study was to conduct a GWAS analysis using individual cheese yield $\left(\mathbf{\%}_{\mathbf{C}} \mathbf{C} \mathbf{Y U R D}_{\mathbf{C U}}\right.$, $\% \mathrm{CY}_{\text {SOLIDS }}$, and $\left.\% \mathrm{CY}_{\text {WATER }}\right)$ and milk nutrient and energy recovery into the curd measures $\left(\mathbf{R E C} \mathbf{C}_{\mathbf{F A T}}\right.$, $\mathbf{R E C}_{\text {PRoteIN }}, \mathbf{R E C}_{\text {SOLIDS }}$, and $\mathbf{R E C}_{\text {ENERGY }}$ ) to shed light on the genetics underlying a cow's cheese-making ability. An Italian Brown Swiss dairy cattle sample genotyped with a 50k SNP chip and with all cheese-making traits measured through individual model-cheese manufacture was used.

\section{MATERIALS AND METHODS}

\section{Field Data}

Milk and blood samples were collected from 1,264 Italian Brown Swiss cows reared in 85 herds located in Trento Province (Italy). A full description of the sampling procedure can be found in Cecchinato et al. (2013). In brief, 15 cows per herd were individually sampled once (evening milking) and all samples were processed within $20 \mathrm{~h}$ after collection. Information on cows and herds was supplied by the Breeders Association of Trento Province.

\section{Definition of Phenotypes}

The phenotypes were obtained through a model cheese-making procedure on $1,500 \mathrm{~mL}$ of milk for each 
cow. The phenotype of interest (i.e., individual cheese yield) was split into 7 components forming 2 groups of traits. The traits analyzed were (1) $3 \% \mathrm{CY}$ traits, expressing the weight $(\mathrm{wt})$ of fresh curd $\left(\% \mathrm{CY}_{\mathrm{CURD}}\right)$, of curd DM (\% $\left.\mathrm{CY}_{\text {SOLIDS }}\right)$, and of water retained in the curd $\left(\% \mathrm{CY}_{\text {WATER }}\right)$ as percentage of weight of milk processed, and (2) 4 REC traits representing the proportion of nutrients and energy of the milk retained in the curd $\left(\mathrm{REC}_{\text {SOLIDS }}, \mathrm{REC}_{\mathrm{FAT}}, \mathrm{REC}_{\mathrm{PROTEIN}}\right.$, and RE$\mathrm{C}_{\text {ENERGY }}$ calculated as the $\%$ ratio between the nutrient in curd and the corresponding nutrient in processed milk). The energy within the curd was calculated as the difference between energy in the milk and in the whey (NRC, 2001). A detailed description of the individual model cheese-making procedure used to obtain the phenotypes analyzed in this study as well as sources of phenotypic variation can be found in Cipolat-Gotet et al. (2013).

\section{Genotyping}

In total, 1,152 cows were genotyped using the Illumina BovineSNP50 v.2 BeadChip (Illumina Inc., San Diego, CA). Markers that fulfilled the following criteria were kept in the analysis: (1) call rate $>95 \%,(2)$ minor allele frequency $>0.005$, and (3) no extreme deviation from Hardy-Weinberg proportions $(P>0.001$, Bonferroni corrected). After quality control, 1,011 animals and 37,568 SNP, distributed over 29 autosomes and the $\mathrm{X}$-chromosome, were retained.

\section{Genome-Wide Association Analyses}

The association analysis was conducted using the GenABEL package in R ( $\mathrm{R}$ Core Team, 2013; GenABEL project developers, 2013). The genome-wide association using mixed model and regression-genomic control (GRAMMAR-GC) approach was adopted, using the default function "gamma" (Amin et al., 2007; Svishcheva et al., 2012). For graphical representation of GWAS results, the R package "qqman" was used (Turner, 2014). The GRAMMAR-GC is a 3-step approach. First, an additive polygenic model is fitted using the genomic relationship matrix. At this step, our model was

$$
\mathbf{y}=\mathbf{X} \boldsymbol{\beta}+\mathbf{a}+\mathbf{e},
$$

where $\mathbf{y}$ is a vector containing the phenotypic records; $\boldsymbol{\beta}$ is a vector with the effects of days in milk of each cow (defined as classes of $30 \mathrm{~d}$ each), parity level of the cow (with classes 1,2,3, $\geq 4$ ), and herd date (85 total), all considered as fixed; and $\mathbf{X}$ is an incidence matrix that associates each observation to specific levels of factors in $\boldsymbol{\beta}$. These nongenetic factors have already been studied in the same data set (Bittante et al., 2013; CipolatGotet et al., 2013). The random effects in the model consisted of the animal and the residual terms, which were assumed normally distributed as $\mathbf{a} \sim N\left(0, \mathbf{G} \sigma_{g}^{2}\right)$ and $\mathbf{e} \sim N\left(0, \mathbf{I} \sigma_{e}^{2}\right)$, where $\mathbf{G}$ is the genomic relationship matrix, $\mathbf{I}$ is an identity matrix, and $\sigma_{g}^{2}$ and $\sigma_{e}^{2}$ are the additive genomic and residual variances, respectively. The G matrix was constructed within the GenABEL R package, where for a given pair of individuals $i$ and $j$, the identical by state coefficients $\left(f_{i, j}\right)$ are calculated as

$$
f_{i, j}=\frac{1}{N} \sum_{k} \frac{\left(x_{i, k}-p_{k}\right) \times\left(x_{j, k}-p_{k}\right)}{p_{k} \times\left(1-p_{k}\right)},
$$

where $N$ is the number of markers used, $x_{i, k}$ is the genotype of the $i$ th individual at the $k$ th SNP (coded as 0 , $1 / 2$, and 1$), p_{k}$ is the frequency of the + allele, and $k$ $=1, \ldots, N$.

Then, at the second step of GRAMMAR-GC, the residuals obtained in (1) are regressed on the SNP (single marker regression) to test for associations. In the last step, the Genomic Control (GC) approach corrects for conservativeness of the GRAMMAR procedure and gives estimates of the marker effects (Svishcheva et al., 2012). A threshold of $P$-value equal to $5 \times 10^{-5}$ was adopted to declare significant associations (Wellcome Trust Case Control Consortium, 2007). The variance explained by each SNP was calculated as $2 \mathrm{pqa}^{2}$, where $p$ is the frequency of one allele, $q=1-p$ is the frequency of the second allele, and a is the estimated additive genetic effect. A scan for genes around $1 \mathrm{Mbp}$ upstream-downstream from the significant SNP was performed using the Ensembl Bos taurus UMD3.1 database (http://www.ensembl.org/index.html).

Model [1] was also used to estimate variance components and genomic heritability of the traits based on the genomic relationship matrix. Heritability was estimated as $\mathrm{h}^{2}=\frac{\sigma_{g}^{2}}{\sigma_{g}^{2}+\sigma_{e}^{2}}$.

\section{RESULTS}

\section{Descriptive Statistics and Genetic Parameters}

Descriptive statistics of the 7 phenotypes analyzed in GWAS as well as milk yield and milk quality traits (fat and protein percentage) are presented in Table 1. The $\% \mathrm{CY}_{\text {CURD }}$ had a mean value of $14.95 \%$ (meaning that from $1.5 \mathrm{~L}$ of milk $\sim 225 \mathrm{~g}$ of fresh cheese was obtained, on average) ranging between 10.2 and $20.5 \%$. 
Table 1. Descriptive statistics of individual percentage cheese yield (\% CY; weight of fresh curd, curd solids, and curd water as a percentage of weight of milk processed), milk nutrient and energy recovery (REC; protein, fat, solids, and energy of the curd as a percentage of the protein, fat, solids, and energy of the milk processed) obtained from $1.5 \mathrm{~L}$ of milk processed, and milk yield and quality traits $(\mathrm{n}=1,011)^{1}$

\begin{tabular}{lrrrrr}
\hline Trait & Mean & SD & P1 & P99 & CV (\%) \\
\hline Cheese yield (\%) & & & & & \\
\%CY CURD & 14.95 & 1.84 & 11.00 & 19.41 & 12.4 \\
\%CY SOLIDS & 7.17 & 0.91 & 5.37 & 9.68 & 12.9 \\
\%CY & 7.77 & 1.26 & 5.04 & 11.11 & 16.3 \\
Nutrient recovery (\%) & & & & & \\
REC $_{\text {SOLIDS }}$ & 51.80 & 3.50 & 43.85 & 60.27 & 6.8 \\
REC $_{\text {FAT }}$ & 89.76 & 3.60 & 78.44 & 95.90 & 4.0 \\
REC $_{\text {PROTEIN }}$ & 78.16 & 2.44 & 72.41 & 83.44 & 3.1 \\
REC ENERGY & 67.15 & 3.28 & 58.92 & 75.07 & 4.9 \\
Milk trait & & & & & \\
Milk yield (kg/d) & 24.95 & 7.84 & 9.30 & 45.89 & 31.4 \\
Fat (\%) & 4.37 & 0.89 & 2.48 & 7.40 & 20.4 \\
Protein (\%) & 3.71 & 0.41 & 2.93 & 4.68 & 10.9 \\
\hline
\end{tabular}

${ }^{1} \mathrm{P} 1$ : 1st percentile; P99: 99th percentile.

On average, the quantity of water retained in the curd was slightly higher than the quantity of the curd solids (7.77 vs. $7.17 \%$, respectively). The highest level of recovery from milk to cheese was observed for fat (mean of $89.76 \%$ ), followed by protein $(78.16 \%$ ) and energy $(67.15 \%)$. The $\mathrm{REC}_{\text {SOLIDS }}$ showed the lowest mean value $(51.80 \%)$ because of the loss of most of the lactose and minerals with whey. For the same data set, the average milk yield was $24.95 \mathrm{~kg} / \mathrm{d}$. The milk fat and protein percentages had average values of 4.37 and $3.71 \%$, respectively.

Genomic variance components and heritability estimates are presented in Table 2. The recovery of the milk protein in cheese had the highest heritability (0.46). For the rest of the traits, the $\mathrm{h}^{2}$ estimates were 0.29 for $\% \mathrm{CY}_{\text {SOLIDS }}$ and $\mathrm{REC}_{\text {SOLIDS }}$ and 0.37 for $\% \mathrm{CY}_{\text {CURD }}$, whereas for \%CY $\mathrm{CHATER}_{\text {and }}$ REC $\mathrm{C}_{\text {ENERGY }}$ they

Table 2. Additive genomic variance $\left(\sigma_{g}^{2}\right)$ and heritability estimates $\left(\mathrm{h}^{2}\right)$ of individual percentage cheese yield $(\% \mathrm{CY}$; weight of fresh curd, curd solids, and curd water as percentage of weight of milk processed) and milk nutrient and energy recovery (REC; protein, fat, solids, and energy of the curd as percentage of the protein, fat, solids, and energy of the milk processed)

\begin{tabular}{|c|c|c|}
\hline Trait & $\sigma_{g}^{2}$ & $\mathrm{~h}^{2}$ \\
\hline \multicolumn{3}{|c|}{ Cheese yield (\%) } \\
\hline$\% \mathrm{CY}_{\mathrm{CURD}}$ & 0.662 & 0.366 \\
\hline$\% \mathrm{CY}_{\text {SOLIDS }}$ & 0.151 & 0.290 \\
\hline$\% \mathrm{CY}_{\text {WATER }}$ & 0.205 & 0.262 \\
\hline \multicolumn{3}{|c|}{ Nutrient recovery (\%) } \\
\hline $\mathrm{REC}_{\text {SOLIDS }}$ & 2.222 & 0.287 \\
\hline $\mathrm{REC}_{\mathrm{FAT}}$ & 1.109 & 0.144 \\
\hline REC $_{\text {PROTEIN }}$ & 1.666 & 0.458 \\
\hline $\mathrm{REC}_{\text {ENERGY }}$ & 1.810 & 0.241 \\
\hline
\end{tabular}

were estimated at $\sim 0.25$. The lowest $h^{2}$ was found for $\mathrm{REC}_{\mathrm{FAT}}$ (0.14).

\section{Results of the Genome-Wide Associations}

In total, 103 significant associations (88 SNP) were identified $\left(P<5 \times 10^{-5}\right)$ on 10 chromosomes (BTA2, BTA6, BTA9, BTA11, BTA12, BTA14, BTA18, BTA19, BTA27, and BTA28; Table 3, Supplemental Table S1; https://doi.org/10.3168/jds.2016-11586). Sharp peaks were identified on BTA6 and BTA11 for the REC ${ }_{F A T}$ and the $\mathrm{REC}_{\text {PROTEIN }}$, respectively. The most frequently identified chromosome was BTA6, representing 55 out of 103 total associations (53\%). This chromosome together with BTA11 accounted for $92 \%$ of the total significant associations. With the exception of BTA6, all the remaining hits were one trait, one chromosome associations. The quantile-quantile plots (scatter plot of the observed vs. expected values of test statistics derived from the GWAS analyses) were also inspected. The quantile-quantile plots showed extreme departures on the tail of the distributions for all traits, except for $\% \mathrm{CY}_{\text {WATER }}$, providing extra evidence for true associations of the GWAS analyses (Supplemental Figure S1; https://doi.org/10.3168/jds.2016-11586).

On BTA6, all traits but $\% \mathrm{CY}_{\text {WATER }}$ and $\mathrm{REC}_{\text {PROTEIN }}$ showed signals (Table 3, Figure 1). Three regions can be distinguished on BTA6. In the first region (6a) at $\sim 73.7$ to $74.6 \mathrm{Mbp}$, the $\mathrm{REC}_{\mathrm{FAT}}$ was linked. The second region ( $6 \mathrm{~b}$; at $\sim 77.5-88.4 \mathrm{Mbp}$ ) was a broader one and all of the 5 traits showed signals, with REC $_{\mathrm{FAT}}$ showing the maximum number of associations among those traits. Finally, \% $\mathrm{CY}_{\mathrm{CURD}}$ was associated with one marker at $\sim 102.9 \mathrm{Mbp}$ (region $6 \mathrm{c}$ ). The highest significant marker on BTA6 was Hapmap52348-rs29024684 $(87,396,306 \mathrm{bp})$. This SNP was the highest significantly identified for $\mathrm{REC}_{\mathrm{SOLIDS}}, \mathrm{REC}_{\mathrm{FAT}}$, and $\mathrm{REC}_{\text {ENERGY }}(P$ value of $3.93 \times 10^{-7}, 1.91 \times 10^{-15}$, and $8.03 \times 10^{-7}$, for $\mathrm{REC}_{\mathrm{SOLIDS}}, \mathrm{REC}_{\mathrm{FAT}}$, and $\mathrm{REC}_{\text {ENERGY }}$, respectively).

A total of 38 SNP were significant on BTA11 at an area spanned between 91.6 to $106.7 \mathrm{Mbp}$. All of the SNP were associated with REC $_{\text {ProteIn }}$ (Table 3, Figure 2 ). The area could further be partitioned into 3 subregions: between 91.6 and 94.8 (11a), 96.2 and 98.5 (11b), and 100.5 and 106.7 (11c) Mbp. In the last area, 25 SNP were significant. Moreover, the most significant SNP was identified within this area, namely marker ARS-BFGL-NGS-104610 (104,293,559bp) with a $P$ value $=6.07 \times 10^{-36}$.

Apart from BTA6 and BTA11 signals in 8 more chromosomes were detected for $\% \mathrm{CY}_{\text {SOLIDS }} \% \mathrm{CY}_{\text {WATER }}$, and

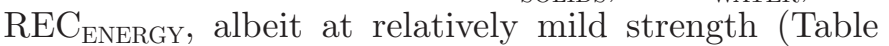
3 , Figure 3). More precisely, $\% \mathrm{CY}_{\text {SOLIDS }}$ was linked to BTA2 ( 128.8 Mbp), BTA14 ( 26 Mbp), BTA19 ( 1.8 


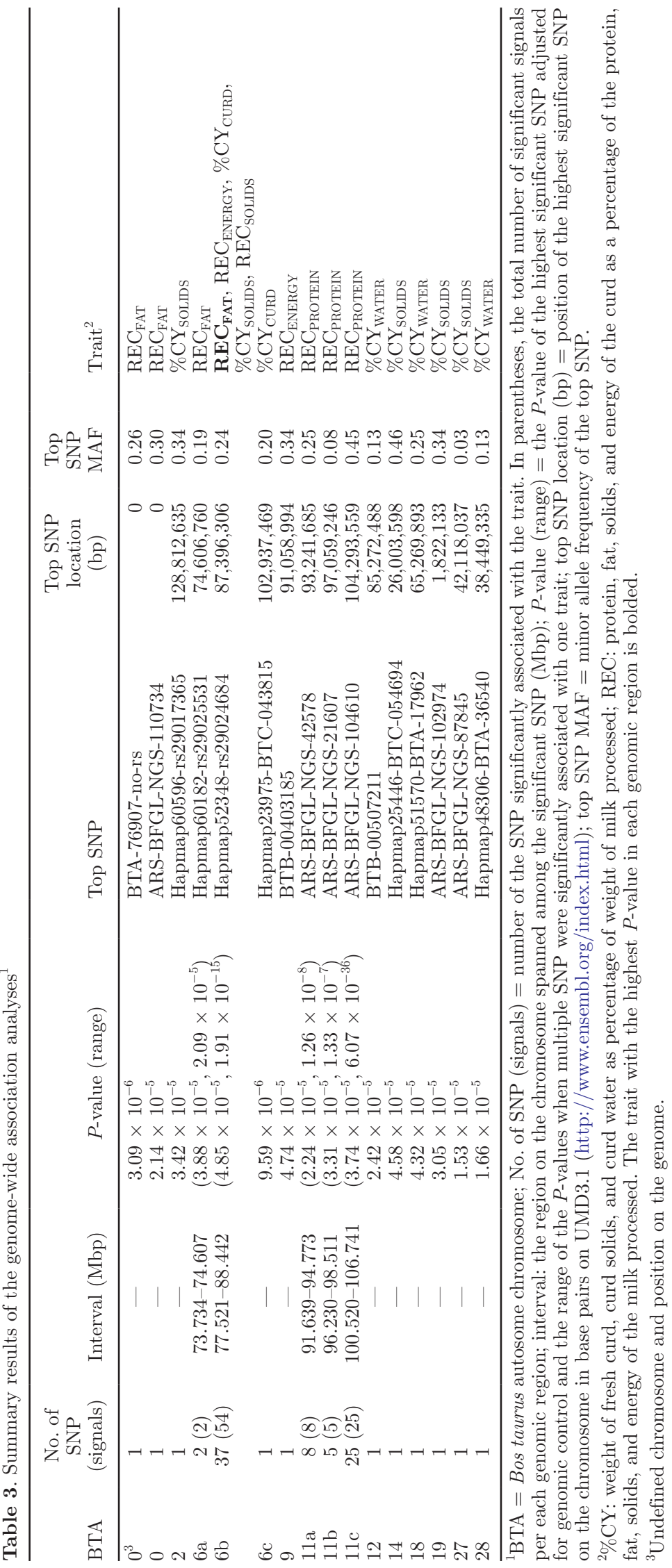



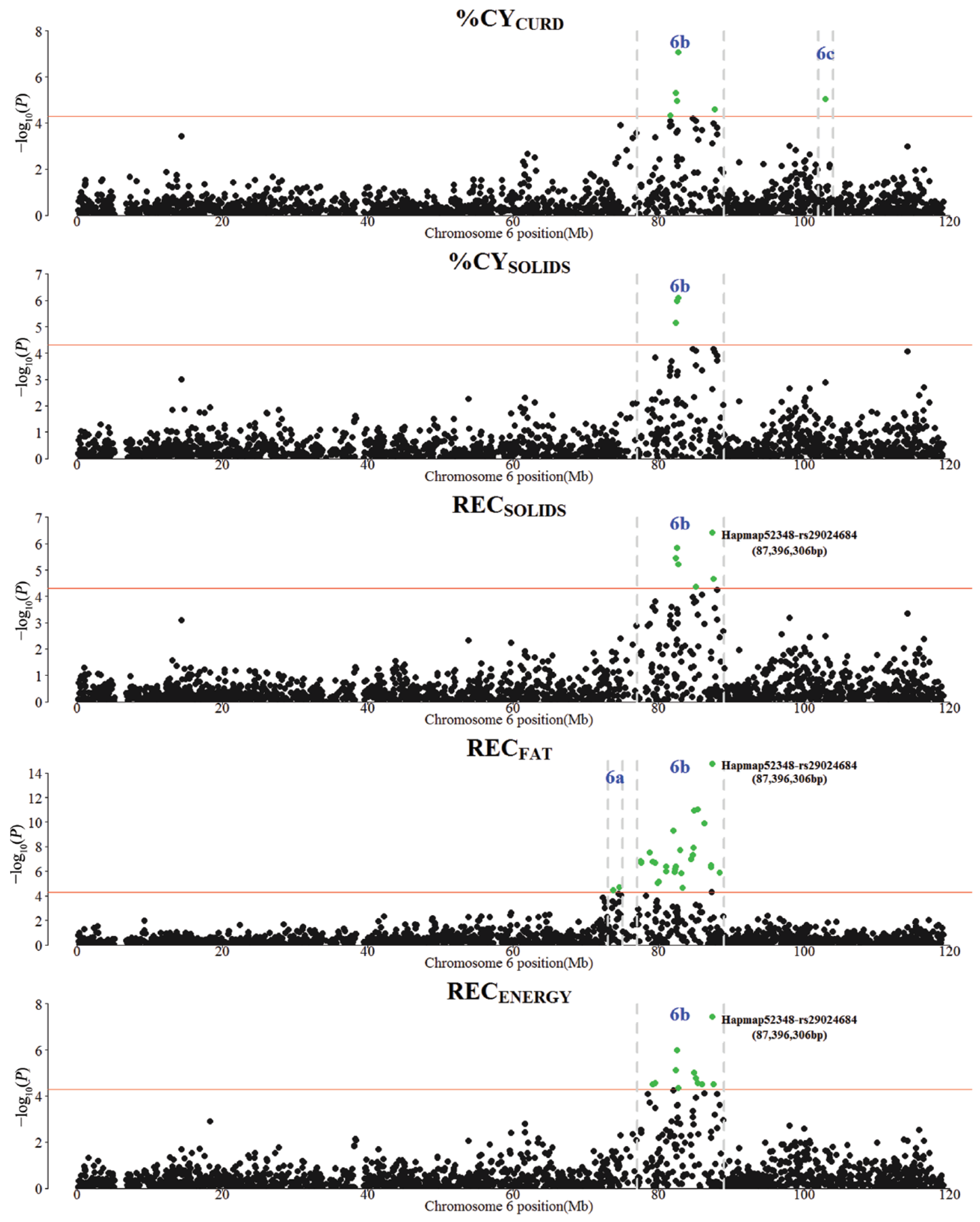

Figure 1. Manhattan plot of $-\log (P$-values $)$ for the genome-wide association studies on Bos taurus autosome 6 (BTA6). Traits that showed significant associations on BTA6 were individual percentage cheese yield traits (\%CY; weight of fresh curd, and curd solids, as a percentage of weight of milk processed) and milk nutrient and energy recovery traits (REC; fat, solids, and energy of the curd as percentage of the fat, solids, and energy of the milk processed). The (red) horizontal lines indicate a $-\log _{10}\left(P\right.$-value) of 4.30 (corresponding to $P$-value $\left.=5 \times 10^{-5}\right)$. The highest significant marker on BTA6 is also presented. Color version available online. 
Mbp), and BTA27 ( 42.1 Mbp). Three markers were significantly associated with the $\% \mathrm{CY}_{\text {WATER }}$ on BTA12 ( $\sim 85.3 \mathrm{Mbp})$, BTA18 ( 65.3 Mbp), and BTA28 ( 38.5 Mbp). Finally, on BTA9 ( 91.1 Mbp), a signal for RE$\mathrm{C}_{\text {ENERGY }}$ was detected.

Comparing the 2 sets of traits (CY vs. REC), the 3 cheese yield traits were associated with 13 SNP in 8 chromosomes (BTA2, BTA6, BTA12, BTA14, BTA18, BTA19, BTA27, and BTA28), whereas the 4 nutrient and energy recoveries of milk into the cheese curd showed associations (76 SNP) on BTA6, BTA9, and BTA11. The only genomic region in common between the 2 groups of traits was the area $6 \mathrm{~b}$ on BTA6, and more precisely the region $\sim 82.5$ to $88 \mathrm{Mbp}$. In this area, 3 significant SNP were in common between $\% \mathrm{CY}_{\mathrm{CURD}}$, $\% \mathrm{CY}_{\text {SOLIDS }}, \mathrm{REC}_{\text {SOLIDS }}$, and $\mathrm{REC}_{\text {ENERGY }}$ (namely, Hapmap26275-BTC-043486, Hapmap50464-BTA-77021, and Hapmap53172-rs29012675), all of which were located in the area around $82 \mathrm{Mbp}$.

\section{Fitting Hapmap52348-rs29024684 ( 87.4 Mbp) on BTA6 and ARS-BFGL-NGS-104610 ( 104.3 Mbp) on BTA11}

Based on the GWAS results and the high peaks identified on BTA6 and BTA11, a further GWAS analysis (conditional GWAS) was followed up by fitting simultaneously as covariates in model [1] the 2 highest significant SNP, to account for the effect of the casein variants and their quantity in milk. In this case, a total of 43 associations (26 SNP) were detected in 8 chromosomes (Table 4, Supplemental Table S2; https://doi. org/10.3168/jds.2016-11586). The number of significant SNP for $\mathrm{REC}_{\mathrm{FAT}}$ and $\mathrm{REC}_{\text {PRotein }}$ drastically decreased (6 and 5, respectively). Moreover, $\mathrm{REC}_{\text {Protein }}$ showed new associations on BTA6 (at $~ 85.6$ and $88 \mathrm{Mbp}$ ) and BTA22 ( 38.8 Mbp), whereas associations for $\mathrm{REC}_{\mathrm{FAT}}$ were still detected on BTA6 (at $\sim 82.5,87.2$, and 88.5 $\mathrm{Mbp}$ ). In general, results changed in 2 directions, namely some regions that were significant in the first analysis did not show significance in the second analysis, and vice versa. In addition, changes occurred in chromosomes as well as positions within chromosomes where significant SNP were located. For example, $\% \mathrm{CY}_{\mathrm{CURD}}$ was now associated with 2 more regions on BTA19 (ARS-BFGL-NGS-102974-1,822,133 Mbp; ARS-BFGL-NGS-24753-3,024,589 Mbp) that were not previously detected. On BTA6, region 6a and part of the $6 \mathrm{~b}$ region (up to $\sim 82 \mathrm{Mbp}$ ) were not confirmed. Three sub-regions could be identified in the $6 \mathrm{~b}$ area at $\sim 82 \mathrm{Mbp}$ (6b_1), $\sim 85-86 \mathrm{Mbp}$ (6b_2), and 87.2-88.6 Mbp (6b_3). The region 6c remained significant. However, an extra signal was detected at $\sim 114 \mathrm{Mbp}$ associated with the $\% \mathrm{CY}_{\text {SOLIDS}}$. Interestingly enough, all the minor alleles of the significant markers on BTA6 had now positive effects, for all traits (Supplemental

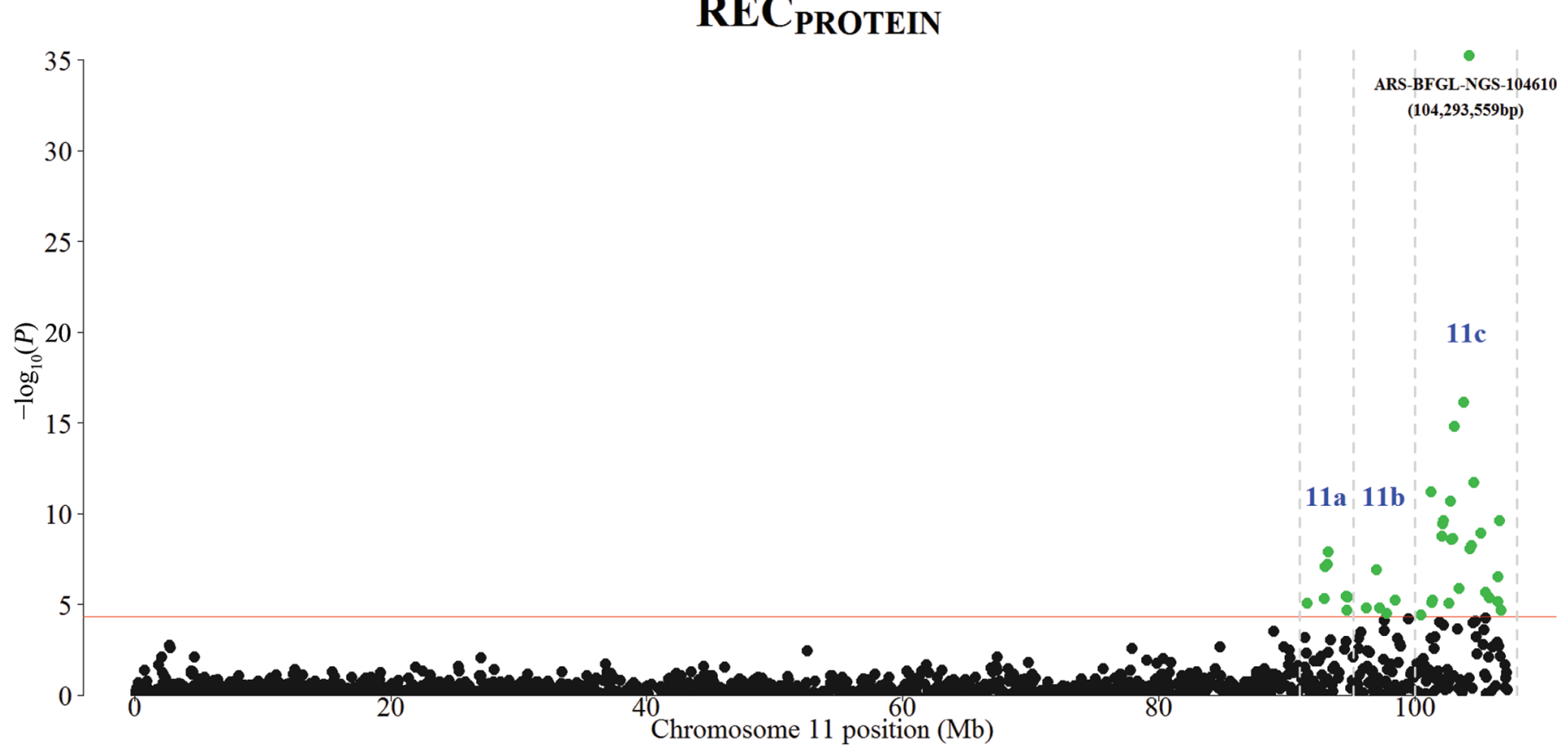

Figure 2. Manhattan plot of $-\log (P$-values $)$ for the genome-wide association studies on BTA11. REC $\mathrm{PROTEIN}=$ protein of the curd as a percentage of the protein of the milk processed. The (red) horizontal line indicates a $-\log _{10}(P$-value $)$ of $4.30\left(\right.$ corresponding to $P$-value $\left.=5 \times 10^{-5}\right)$. The highest significant marker on BTA11 is also presented. Color version available online. 

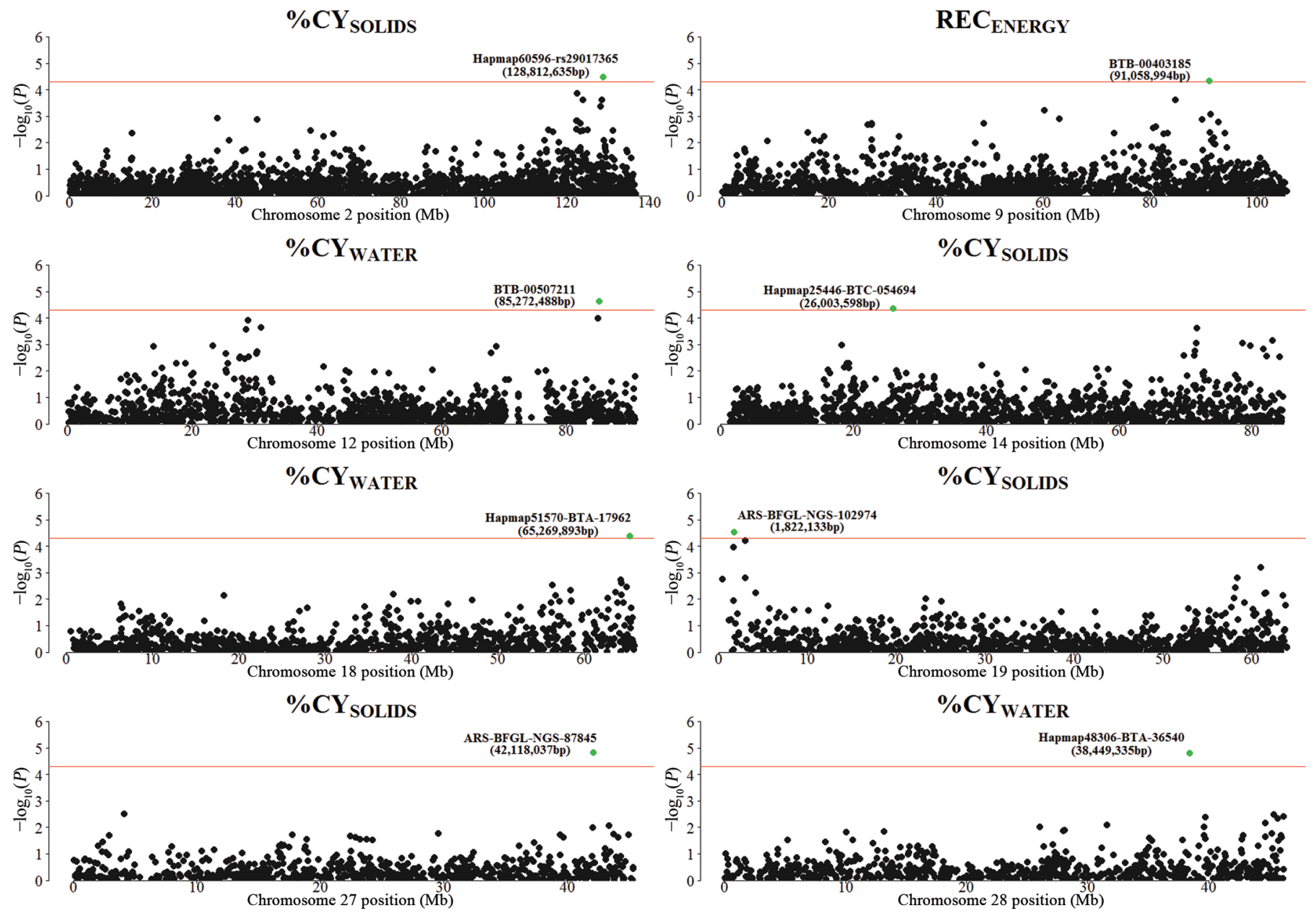

Figure 3. Manhattan plot of $-\log (P$-values $)$ for the genome-wide association studies on BTA2, BTA9, BTA12, BTA14, BTA18, BTA19, BTA27, and BTA28. Traits that showed significant associations were individual percentage cheese yield traits (\%CY; weight of curd solids and water as percentage of weight of milk processed) and energy of the curd as percentage of the energy of the milk processed (REC $\mathrm{ENERGY}$ ). The highest significant marker on each chromosome is also presented. Color version available online.

Table S2; https://doi.org/10.3168/jds.2016-11586). On BTA11, only a signal within the 11c area $(\sim 103.5 \mathrm{Mbp})$ was detected, but in this case $\mathrm{REC}_{\text {PROTEIN }}$ was associated with only 2 SNP. Also in this case, the estimated effects of the minor alleles of the significant SNP on BTA11 were now positive. Signals on BTA2, BTA14, and BTA18 were not identified, whereas the significant associations remained on BTA27 and BTA28. In the conditional analysis, most of the signals were mild with the exception of regions $6 \mathrm{~b} \_1$ and $11 \mathrm{c}$.

\section{DISCUSSION}

\section{Genome-Wide Associations for the Cheese Yield Traits}

Cheese yield is the outcome of a complex process on which a variety of interrelated factors, derived from different disciplines (e.g., microbiology, physical chemistry, engineering process, etc.) are involved, such as (1) the quantity (e.g., caseins and fat) as well as the quality (e.g., the fraction of the caseins to the total milk proteins, and the dimension of fat globules) of milk components; (2) other milk characteristics (e.g., milk acidity, minerals, and microbial flora); (3) milk pre-treatments (e.g., milk natural creaming, heat treatment, and so on); and (4) cheese-making conditions (e.g., coagulation temperature, type, and concentration of rennet, curd cutting, curd cooking, and pressing). To understand this complicated progression, a plethora of studies have been carried out, and a well-documented description of the cheese process is available (Banks, 2007; Law and Tamime, 2011; Walstra et al., 2014), although our knowledge is yet incomplete. Moreover, this knowledge has been built based on bulk milk. From a breeding perspective, however, information on 


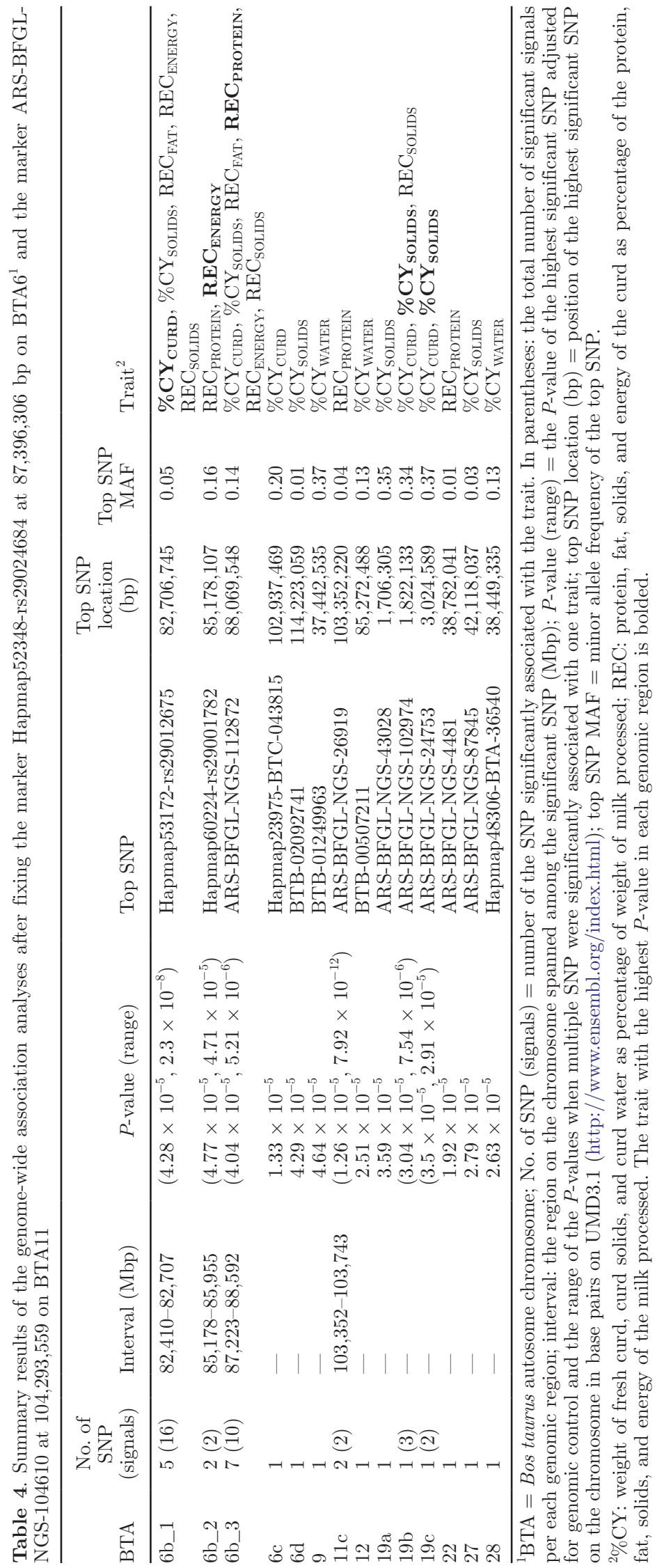


the individual level of the ability of a cow to produce cheese is necessary. Previous analysis indicated that there is considerable variation on the traits of interest, and breeding could help for further improvement (Bittante et al., 2013). The restriction, though, for a wide-scale phenotyping on individual $\mathrm{CY}$ is the lack of an appropriate technology combined with high costs. Identification of chromosomic regions associated with individual CY offers a possible alternative through the application of genomic breeding programs.

Genomic heritability estimates varied between 0.14 to 0.46 . These values are in the same range as those reported in Bittante et al. (2013) from an infinitesimal model. Slight differences might be attributed to the different set-up of statistical model used (e.g., herd was fixed vs. random effect, frequentist vs. Bayesian analysis) and the different number of individuals included. Moreover, here we made use of the genomic relationship matrix, whereas in Bittante et al. (2013), the analysis was carried out using pedigree information.

Previous GWAS studies have linked various milk components and milk technological characteristics related to cheese yield to a variety of chromosomic regions (Schopen et al., 2011; Gregersen et al., 2015; Dadousis et al., 2016). In the present study, for the first time, 7 traits derived from direct cheese measures, representing an individual cow's cheese production ability and obtained from a model cheese-making process, were analyzed. All the traits showed significant associations and were linked to at least one chromosome.

\section{BTA6}

Sharp peaks were detected for $\mathrm{REC}_{\mathrm{FAT}}$ on BTA6 in a broad area between $\sim 77.5$ and $88.5 \mathrm{Mbp}$. In this area the casein cluster is mapped $(\sim 87 \mathrm{Mbp})$. All of the traits analyzed but $\% \mathrm{CY}_{\text {WATER }}$ and $\mathrm{REC}_{\text {PROTEIN }}$ showed associations in this region (Table 3, Figure 3) with the highest peak spotted at $\sim 87 \mathrm{Mbp}$ (marker Hapmap52348-rs29024684; 87,396,306 bp). This marker had a negative effect of the minor allele for all the traits, more precisely $-0.84,-1.34$, and -0.90 for $\mathrm{REC}_{\mathrm{SOLIDS}}, \mathrm{REC}_{\mathrm{FAT}}$, and $\mathrm{REC}_{\text {ENERGY }}$, respectively. For the same traits, the proportion of phenotypic variance explained by this marker was 3.31 and $3.92 \%$ for $\mathrm{REC}_{\text {SOLIDS }}$ and $\mathrm{REC}_{\text {ENERGY }}$, whereas it increased to $8.45 \%$ for $\mathrm{REC}_{\mathrm{FAT}}$. Concerning the percentage of the additive genetic variance explained by this SNP it was found to be $11.5,58.8$, and $16.3 \%$, for $\mathrm{REC}_{\text {SOLIDS }}$, $\mathrm{REC}_{\mathrm{FAT}}$, and $\mathrm{REC}_{\mathrm{ENERGY}}$, respectively (Supplemental Table S1; https://doi.org/10.3168/jds.2016-11586). It is interesting to note that area $6 \mathrm{~b}$ has recently been reported and thoroughly described in a recent GWAS study (Dadousis et al., 2016). In that case, a trait de- fined as the "asymptotic value of curd firmness in the absence of syneresis" showed strong signals exactly in the same region $(\sim 77.5-88.5 \mathrm{Mbp})$. Moreover, marker Hapmap52348-rs29024684 was highly significant for a variety of traits describing milk coagulation and curd firmness $\left(P\right.$-values ranged between $7.46 \times 10^{-07}$ and $\left.1.62 \times 10^{-17}\right)$. The present analysis has confirmed the importance of the casein genes and especially the CSN3 casein gene for an individual cow's cheese yield, because the peak is located only $18 \mathrm{kbp}$ upstream of CSN3. In addition, in this area the marker Hapmap28023BTC-060518 (87.20 Mbp) is also present, which was significantly related to $\operatorname{REC}_{\mathrm{FAT}}(P$-value $=3.36 \times$ $\left.10^{-7}\right)$. The SNP is mapped within the histatherin gene $(H S T N)$, which is located between the CSN2 and the CSN1S2. The same SNP was also reported in Dadousis et al. (2016). Even after conditioning on the peak on BTA6, signals still remained at $\sim 82.71, \sim 85.1, \sim 87.22$, and $\sim 88.1 \mathrm{Mbp}$, giving evidence for potential new QTL (Table 4; Supplemental Table S2, https://doi. org/10.3168/jds.2016-11586).

The region around $88 \mathrm{Mbp}$ has also been linked to different measures of Holstein cow milk protein composition, including the casein variants $C S N 1 S 1, C S N 1 S 2$, $C S N 2$, and $C S N 3$ as well as $\alpha$-lactalbumin $(\alpha-L A), L G B$, the casein index and casein percentage (Schopen et al., 2011). Moreover, a similar peak at 87.2 to $87.4 \mathrm{Mbp}$ has been recently reported in a GWAS study analyzing rheological traits of milk related to milk coagulation in Swedish Red cows (Gregersen et al., 2015). Other regions on BTA6 that have been detected in previous studies on association with milk quality and coagulation traits did not appear significant in our study for the direct measures of cheese-making traits [e.g., the area $\sim 44 \mathrm{Mbp}$ in Schopen et al. (2011), the genomic region 50-51 Mbp (Gregersen et al., 2015; Dadousis et al., 2016), and the areas $\sim 60 \mathrm{Mbp}$ (Gregersen et al., 2015) and $\sim 64 \mathrm{Mbp}$ (Dadousis et al., 2016)]. Nevertheless, the region $6 \mathrm{~d}$ detected in the conditional analysis is in close proximity to the $\sim 113 \mathrm{Mbp}$ that was reported in Dadousis et al. (2016) associated with milk protein (\%).

By using direct cheese traits obtained through a cheese-making process, it has been shown that the importance of this genomic region is related, apart from codification of protein genetic variants, with the recovery of the milk fat into the curd, and not to the recovery of protein. This was, to an extent, expected, because in healthy cows all casein variants are essential for the structure and activity of milk protein micelles (Holt et al., 2013) and participate to the formation of coagula (Caroli et al., 2009) and curd syneresis (Pearse and Mackinlay, 1989; Everard et al., 2011). However, the efficiency of capturing milk fat globules depends 
on the rapidity of clotting and the strength of the curd that in turn depend on casein genetic variants (Alipanah and Kalashnikova, 2007).

\section{BTA11}

Chromosome 11 was only linked to $\mathrm{REC}_{\text {PRotein }}$, with all association hits being detected on the tail of BTA11 (Table 3). On this chromosome, the peak was detected at 104,293,559 bp (marker ARS-BFGL-NGS-104610; $P$-value $\left.=6.07 \times 10^{-36}\right)$, whereas a strong signal at 103.35 Mbp remained in the conditional analysis. The effect of the minor allele of this marker was negative for the $\operatorname{REC}_{\text {PROTEIN }}(-1.30)$. The phenotypic variance explained by this marker was $22.87 \%$, whereas half of the additive genetic variance can be attributed to this SNP. The significance of this region confirms the findings of Schopen et al. (2011), in which significant associations were identified for the casein variants $(\alpha, \beta$, and $\kappa)$ as well as for $\beta-\mathrm{LG}$ content and casein index, although in that case high peaks appeared at $107 \mathrm{Mbp}$. It should be noted that $\mathrm{REC}_{\text {PROTEIN }}$ is phenotypically very similar to the casein index. However, because part of the caseins are lost in the whey, $\mathrm{REC}_{\text {PROTEIN }}$ is able to capture more variation compared with the casein index. The region around 86 to $88 \mathrm{Mbp}$ has been recently associated with $\mathrm{CF}_{\mathrm{t}}$ traits (Dadousis et al., 2016), but it was not confirmed for direct cheese-making traits in our study. Nevertheless, this batch is relatively close to marker BTA-93319-no-rs (91,639,283 bp), which was significant in the present GWAS analysis $(P=8.8 \times$ $\left.10^{-6}\right)$. However, this signal was diluted after conditioning on the BTA11 peak.

A closer look into the region $\pm 1 \mathrm{Mbp}$ around the marker ARS-BFGL-NGS-104610 was performed. This SNP is located $\sim 2.5 \mathrm{kbp}$ downstream of surfeit locus protein 6 (SURF6). In this small area, the following protein coding genes are located: (1) downstream the marker: 1-acyl-sn-glycerol-3-phosphate acyltransferase $\beta$ (AGPAT2), family with sequence similarity 69 , member B (FAM69B), histo-blood group $A B O$ system transferase $(A B O)$, and (2) upstream the marker: mediator of RNA polymerase II transcription subunit 22 (MED22), 60S ribosomal protein L7a (RPFL7A), surfeit locus protein 1 (SURF1), surfeit locus protein 2 (SURF2), serine/threonine kinase-like domain containing 1 (STKLD1), and RNA exonuclease 4 (REXO4). From those protein coding genes, AGPAT2 is involved in fat digestion and absorption as well as in fatty acid metabolic pathways. The gene RPFL7A, among a variety of functions, is also part of biosystem pathways regulating the metabolism of proteins. Moreover, although further apart on the chromosome, within the region spanning $\pm 1 \mathrm{Mbp}$ around the significant marker, the progestagen-associated endometrial protein gene (PAEP, also known as $L G B)$, can be found.

\section{Signals on Other Chromosomes}

Concerning the rest of the chromosomes, one SNPone trait associations were observed in all cases. Moreover, the majority of the $P$-values were around the threshold. The signals on BTA2, BTA14, and BTA18 were not retained after conditioning the peaks on BTA6 and BTA11. Moreover, on BTA14 the significant SNP detected $(\sim 26 \mathrm{Mbp})$ is far apart from diacylglycerol O-acyltransferase 1 (DGAT1). This should not be surprising, mainly for 2 reasons. First, DGAT1 has been associated with milk fat content in dairy cattle. In our study, however, the recovery of the milk fat into the curd was the focal point. The 2 traits are entirely different, both phenotypically and genetically, with almost zero phenotypic and genetic correlations (Bittante et al., 2013). At the beginning of the coagulation process, the fat of the milk is blocked by the caseins. This has been confirmed in our analysis by associating, with high peaks, $\mathrm{REC}_{\mathrm{FAT}}$ to a region on BTA6 where the casein genes are located [see also results of Schopen et al. (2011) on GWAS with milk protein variants]. Moreover, in the Italian Brown Swiss population, DGAT1 is not segregating. Albeit at a mild strength, the same signal on BTA28 has been previously linked to milk protein percentage (Dadousis et al., 2016).

\section{Partitioning the Cheese Yield into Different Components}

As a side note, our study highlighted the importance of partitioning a complex trait into different components for a better understanding of its genomic background. More precisely, the percentage of cheese produced by a given amount of milk was split into 7 different traits. For example, phenotypically $\% \mathrm{CY}_{\mathrm{CURD}}=\% \mathrm{CY}_{\text {SOLIDS }}+$ $\% \mathrm{CY}_{\text {WATER }}$. However, the genomic signals of $\% \mathrm{CY}_{\mathrm{CURD}}$ $\neq \% \mathrm{CY}_{\text {SOLIDS }}+\% \mathrm{CY}_{\text {WATER }}$. On the contrary, 7 out of 8 genomic regions identified for $\% \mathrm{CY}_{\text {SOLIDS }}$ and $\% \mathrm{CY}_{\text {WATER }}$ were not present in $\% \mathrm{CY}_{\mathrm{CURD}}$. Moreover, the marker Hapmap52348, located close to CSN3, was detected only from the recoveries of fat, solids, and energy, whereas the significance of BTA11 was depicted only with the protein recovery.

\section{CONCLUSIONS}

Different measures of bovine cheese ability were associated with 10 chromosomic regions. Five out of the 7 cheese traits used in GWAS analyses showed high peaks on BTA6 $(\sim 87.4 \mathrm{Mbp})$ in an area close to kappa 
casein, confirming the importance of this casein variant in cheese making. Moreover, high peaks on BTA11 $(\sim 104.3 \mathrm{Mbp})$ were linked to milk protein recovery into the curd. Several other chromosomic regions have also been significantly associated with the cheese traits analyzed, albeit in the absence of high peaks. Highly significant markers identified, especially on BTA6 and BTA11, could further be used for genomic prediction purposes. The road for fine mapping of genomic regions associated with a cow's cheese production potential is ahead. Future research based on gene enrichment analysis might complement the GWAS results and help to deepen the understanding of the biological pathways related to the $\mathrm{CY}$ traits. Partition of a complex process, as is the cheese yield, into different components has been shown as a useful tool for connecting phenomics to their genomic counterpart.

\section{ACKNOWLEDGMENTS}

The authors thank the Trento Province (Italy), the Italian Brown Swiss Cattle Breeders Association (ANARB, Verona, Italy) and the Superbrown Consortium of Bolzano and Trento for financial and technical support. C. Dadousis benefitted from financial support of the CARIPARO (Cassa di Risparmio di Padova e Rovigo) Foundation (Padua, Italy).

\section{REFERENCES}

Alipanah, M., and L. Kalashnikova. 2007. Influence of k-casein genetic variant on cheese making ability. J. Anim. Vet. Adv. 6:855-857.

Amin, N., C. M. Van Duijn, and Y. S. Aulchenko. 2007. A genomic background based method for association analysis in related individuals. PLoS One 2:e1274.

Banks, J. M. 2007. Cheese yield. Pages 100-114 in Cheese Problems Solved. P. L. H. McSweeney, ed. Woodhead Publishing Ltd., Cambridge, UK.

Bittante, G., C. Cipolat-Gotet, and A. Cecchinato. 2013. Genetic parameters of different measures of cheese yield and milk nutrient recovery from an individual model cheese-manufacturing process. J. Dairy Sci. 96:7966-7979.

Bittante, G., A. Ferragina, C. Cipolat-Gotet, and A. Cecchinato. 2014 Comparison between genetic parameters of cheese yield and nutrient recovery or whey loss traits measured from individual model cheese-making methods or predicted from unprocessed bovine milk samples using fourier-transform infrared spectroscopy. J. Dairy Sci. 97:6560-6572.

Bittante, G., M. Penasa, and A. Cecchinato. 2012. Invited review: Genetics and modeling of milk coagulation properties. J. Dairy Sci. 95:6843-6870.

Bonfatti, V., G. Di Martino, A. Cecchinato, L. Degano, and P. Carnier. 2010. Effects of $\beta$ - $\kappa$-casein (CSN2-CSN3) haplotypes, $\beta$-lactoglobulin (BLG) genotypes, and detailed protein composition on coagulation properties of individual milk of Simmental cows. J. Dairy Sci. 93:3809-3817.

Bovine Genome Sequencing and Analysis Consortium. C. G. Elsik, R. L. Tellam, and K. C. Worley. 2009. The genome sequence of taurine cattle: A window to ruminant biology and evolution. Science 324:522-528.
Caroli, A. M., S. Chessa, and G. J. Erhardt. 2009. Invited review: Milk protein polymorphisms in cattle: Effect on animal breeding and human nutrition. J. Dairy Sci. 92:5335-5352.

Cecchinato, A., S. Chessa, C. Ribeca, C. Cipolat-Gotet, T. Bobbo, J. Casellas, and G. Bittante. 2015. Genetic variation and effects of candidate-gene polymorphisms on coagulation properties, curd firmness modeling and acidity in milk from brown Swiss cows. Animal 9:1104-1112.

Cecchinato, A., C. Cipolat-Gotet, J. Casellas, M. Penasa, A. Rossoni, and G. Bittante. 2013. Genetic analysis of rennet coagulation time, curd-firming rate, and curd firmness assessed over an extended testing period using mechanical and near-infrared instruments. J. Dairy Sci. 96:50-62.

Cecchinato, A., M. De Marchi, L. Gallo, G. Bittante, and P. Carnier. 2009. Mid-infrared spectroscopy predictions as indicator traits in breeding programs for enhanced coagulation properties of milk. J. Dairy Sci. 92:5304-5313.

Cecchinato, A., C. Ribeca, A. Maurmayr, M. Penasa, M. De Marchi, N. P. P. Macciotta, M. Mele, P. Secchiari, G. Pagnacco, and G. Bittante. 2012. Short communication: Effects of $\beta$-lactoglobulin, stearoyl-coenzyme A desaturase 1, and sterol regulatory element binding protein gene allelic variants on milk production, composition, acidity, and coagulation properties of brown Swiss cows. J. Dairy Sci. 95:450-454.

Chessa, S., O. Bulgari, R. Rizzi, L. Calamari, P. Bani, S. Biffani, and A. M. Caroli. 2014. Selection for milk coagulation properties predicted by Fourier transform infrared spectroscopy in the Italian Holstein-Friesian breed. J. Dairy Sci. 97:4512-4521.

Cipolat-Gotet, C., A. Cecchinato, M. De Marchi, and G. Bittante. 2013. Factors affecting variation of different measures of cheese yield and milk nutrient recovery from an individual model cheesemanufacturing process. J. Dairy Sci. 96:7952-7965.

Dadousis, C., S. Biffani, C. Cipolat-Gotet, E. Nicolazzi, A. Rossoni, E. Santus, G. Bittante, and A. Cecchinato. 2016. Genome-wide association of coagulation properties, curd firmness modeling, protein percentage, and acidity in milk from Brown Swiss cows. J. Dairy Sci. 99:3654-3666.

de Los Campos, G., J. M. Hickey, R. Pong-Wong, H. D. Daetwyler, and M. P. L. Calus. 2013. Whole genome regression and prediction methods applied to plant and animal breeding. Genetics 193:327345.

Everard, C. D., D. J. O'Callaghan, M. J. Mateo, M. Castillo, F. A. Payne, and C. P. O'Donnell. 2011. Effects of milk composition, stir-out time, and pressing duration on curd moisture and yield. J. Dairy Sci. 94:2673-2679.

Ferragina, A., C. Cipolat-Gotet, A. Cecchinato, and G. Bittante. 2013. The use of Fourier-transform infrared spectroscopy to predict cheese yield and nutrient recovery or whey loss traits from unprocessed bovine milk samples. J. Dairy Sci. 96:7980-7990.

Food and Agriculture Organization of the United Nations. 2015 FAOSTAT. Accessed Mar. 27, 2015. http://www.milb.com/index. jsp?sid=t564.

GenABEL project developers. 2013. GenABEL: Genome-wide SNP association analysis. $\mathrm{R}$ package version $1.8-0$. http://CRAN.Rproject.org/package $=$ GenABEL

Glantz, M., H. Lindmark Månsson, H. Stålhammar, and M. Paulsson. 2011. Effect of polymorphisms in the leptin, leptin receptor, and acyl-coenzyme A:Diacylglycerol acyltransferase 1 (DGAT1) genes and genetic polymorphism of milk proteins on cheese characteristics. J. Dairy Sci. 94:3295-3304.

Goddard, M. E., and B. J. Hayes. 2009. Mapping genes for complex traits in domestic animals and their use in breeding programmes. Nat. Rev. Genet. 10:381-391.

Gregersen, V. R., F. Gustavsson, M. Glantz, O. F. Christensen, H. Stålhammar, A. Andrén, H. Lindmark-Månsson, N. A. Poulsen, L. B. Larsen, and M. Paulsson. 2015. Bovine chromosomal regions affecting rheological traits in rennet-induced skim milk gels. J. Dairy Sci. 98:1261-1272.

Holt, C., J. A. Carver, H. Ecroyd, and D. C. Thorn. 2013. Invited review: Caseins and the casein micelle: Their biological functions, structures, and behavior in foods. J. Dairy Sci. 96:6127-6146. 
Hurtaud, C., H. Rulquin, M. Delaite, and R. Vérité. 1995. Appréciation de l'aptitude fromagère des laits de vaches individuels. Tests d'aptitude fromagère et rendement fromager de fabrication. Ann. Zootech. 44:385-398.

International Committee for Animal Recording (ICAR). 2012. International agreement of recording practices - Guidelines approved by the general assembly held in Cork, Ireland on June 2012. ICAR, Rome, Italy.

Law, B. A., and A. Y. Tamime. 2011. Technology of Cheesemaking. John Wiley \& Sons, Hoboken, NJ.

McCarthy, M. I., G. R. Abecasis, L. R. Cardon, D. B. Goldstein, J. Little, J. P. Ioannidis, and J. N. Hirschhorn. 2008. Genome-wide association studies for complex traits: Consensus, uncertainty and challenges. Nat. Rev. Genet. 9:356-369.

NRC. 2001. Nutrient Requirements of Dairy Cattle. 7th rev. ed. Natl. Acad. Press, Washington, DC.

Othmane, M. H., J. A. Carriedo, L. F. de la Fuente Crespo, and F. San Primitivo. 2002. An individual laboratory cheese-making method for selection in dairy ewes. Small Rumin. Res. 45:67-73.

Pearse, M. J., and A. G. Mackinlay. 1989. Biochemical aspects of syneresis: A review. J. Dairy Sci. 72:1401-1407.

R Core Team. 2013. R: A language and environment for statistical computing. http://www.R-project.org/.

Rutten, M. J. M., H. Bovenhuis, K. A. Hettinga, H. J. F. van Valenberg, and J. A. M. van Arendonk. 2009. Predicting bovine milk fat composition using infrared spectroscopy based on milk samples collected in winter and summer. J. Dairy Sci. 92:6202-6209.

Schopen, G. C. B., M. H. P. W. Visker, P. D. Koks, E. Mullaart, J. A. M. van Arendonk, and H. Bovenhuis. 2011. Whole-genome associa- tion study for milk protein composition in dairy cattle. J. Dairy Sci. 94:3148-3158.

Svishcheva, G. R., T. I. Axenovich, N. M. Belonogova, C. M. van Duijn, and Y. S. Aulchenko. 2012. Rapid variance componentsbased method for whole-genome association analysis. Nat. Genet. 44:1166-1170.

Turner, S. D. 2014. Qqman: An R package for visualizing GWAS results using Q-Q and Manhattan plots. bioRxiv https://doi. org $/ 10.1101 / 005165$.

Tyrisevä, A., K. Elo, A. Kuusipuro, V. Vilva, I. Jänönen, H. Karjalainen, T. Ikonen, and M. Ojala. 2008. Chromosomal regions underlying noncoagulation of milk in Finnish Ayrshire cows. Genetics 180:1211-1220.

Van Eenennaam, A. L., K. A. Weigel, A. E. Young, M. A. Cleveland, and J. C. Dekkers. 2014. Applied animal genomics: Results from the field. Annu. Rev. Anim. Biosci. 2:105-139.

Visscher, P. M., M. A. Brown, M. I. McCarthy, and J. Yang. 2012. Five years of GWAS discovery. Am. J. Hum. Genet. 90:7-24.

Walstra, P., P. Walstra, J. T. Wouters, and T. J. Geurts. 2014. Dairy Science and Technology. CRC Press, Boca Raton, FL.

Wedholm, A., L. B. Larsen, H. Lindmark-Månsson, A. H. Karlsson, and A. Andrén. 2006. Effect of protein composition on the cheesemaking properties of milk from individual dairy cows. J. Dairy Sci. 89:3296-3305.

Wellcome Trust Case Control Consortium. 2007. Genome-wide association study of 14,000 cases of seven common diseases and 3,000 shared controls. Nature 447:661-678 